\title{
Rubén Darío y Claude Debussy. La catedral sumergida y la Sinfonía en gris mayor
}

José Manuel Rojas González

Lo que interesa en este trabajo es establecer un nexo entre el trabajo poético de un escritor y la composición de un músico: ise puede trabajar con la literatura y la música y crear un nexo entre ellas? Es una pregunta que se ha formulado frecuentemente y a la cual se tratará de responder positivamente.

En la cultura occidental, muchos escritores han compuesto refiriéndose a la música, lo que implica que el fenómeno musical, para ser explicado, necesita de las palabras mientras que, por el otro lado, el lenguaje tiene muchas propiedades acústicas.

Los mismos teóricos de la música utilizan el idioma, las palabras para analizar y divulgar sus ideas acerca del fenómeno musical.

La propiedad sonora de las palabras y de los discursos, en cambio, ha sido explotada, al menos en América latina, 
empezando por Darío, Ruidobro, Vallejo, Lugones, Neruda, Carpentier, Cortázar, Paz, García Márquez, Borges, hasta llegar a Fuentes. Recordamos que, en el libro Evaristo Carriego (1930) de Jorge Luis Borges encontramos una de las más agudas explicaciones sobre el tango.

La catedral sumergida es la traducción del título La cathédral engloutie, del décimo preludio para piano, den el primer libro de los Préludes (Preludios, 1910) compuesto por Claude Debussy tomando inspiración de una antigua leyenda bretona.

Los Préludes refuerzan más que cualquier otra obra la idea de que Debussy escribió música impresionista. No olvidemos que Claude Debussy escribió en el título final de la pieza que él no quiere que se tenga enseguida una imagen determinada ante los ojos. Prefiere hacer una confirmación una vez escuchada la obra.

En estas páginas musicales de Debussy no es la tonalidad la que determina la forma, sino más bien la construcción sonora, la melodía, el ritmo. La tonalidad es el descubrimiento más importante de la historia de la música occidental, por eso nosotros escuchamos la música en modo mayor y en modo menor y, en la música occidental, forma el centro de gravedad de una composición. Por lo tanto, si escuchamos una sinfonía o un bolero, estos dos géneros musicales van a girar en torno a un eje, que será la tonalidad específica que el compositor escoge. De allí que se van uniendo las dos vertientes: Debussy-Darío Ambos fueron músicos y ambos fueron escritores; Darío tocaba piano (Chopin, sobre todo) y Debussy fue crítico de música: entre sus libros podemos citar Monsieur Croche et autres ècrits ( $E l$ señor Corchea y otros escritos, 1910).

El investigador de la música puede comprobar la evolución de las canciones de Debussy, que toma inspiración desde Baudelaire hasta Pierre Louys, el alejamiento artístico 
de Wagner y la creación del estilo nuevo, moderado, susurrante, de Peleas.

Debussy, en los cafés, tales como la Taverne Royale o el famoso Weber se reúne con los escritores Leòn Tardieu, Charles de Chambrun, Reynaldo Hahn y Marcel Proust. Proust, el más prestigioso de este círculo, busca el contacto con Debussy. Incluso quiere hacer conciertos con su música. Debussy le esquiva: Sabe usted, yo soy un oso. Prefiero verle en el café. No se enfade, yo soy así... (Debussy, 1986).

\section{El compositor y el poeta}

El intento de relacionar a Debussy con Rubén Darío se centra en el análisis comparativo de La Catedral sumergida con Sinfonía en gris mayor, un poema de Rubén Darío que pertenece al libro que se llama Cantos de vida y esperanza (1903).

La primera relación que podemos notar en ambos trabajos, la obra de Debussy y el poema de Darío es el contacto con el agua. Recordemos que el mismo Debussy dijo que si él no hubiera sido compositor, hubiera sido marinero, y definitivamente hay una presencia continua del elemento acuático en sus composiciones, en algunos casos reflejada por el título: La Mer, (1905) Nocturnes, (1899) Reflets dans l'eau de Images, Serie I, (1905), de la Petite Suite para piano a cuatro manos (1888).

Como dato curioso, En bateau, escrita en el mismo año de Azul de Darío, coincidió con el viaje de Debussy a Bayreuth, Alemania, para asistir a las representaciones de las óperas de Wagner: Parsifal y Los Maestros Cantores.

Nos podemos atrever a decir hasta aquí que la tonalidad en Debussy se basó, durante toda su vida, en su relación con el agua.

Y ya Darío comienza el poema así: 
El mar como un vasto cristal azogado, Refleja la lámina de un cielo de zinc;

Lejanas bandadas de pájaros manchan

El fondo bruñido de pálido gris.

Otro elemento análogo en ambos trabajos es el espacio. Debussy con una catedral que está inmersa en el agua y comienza a subir a flote nos transmite la imagen interior de un objeto inmenso. Darío comienza el título de su poema con la palabra "Sinfonía": considero revolucionario, desde todo punto de vista, nombrar un poema "Sinfonía", sobre todo porque es el nombre de un género musical; más aún: hablando de espacio, el término denota, desde el punto de vista formal, un espacio vasto. Debussy en cambio llama "Preludio" a una composición que dibuja mentalmente una catedral. El Preludio es un género musical corto, pequeño, un espacio musical pequeño. Sin embargo ambos desarrollan el tema del espacio: el mar visto como un vasto cristal azogado en Darío, mientras que Debussy construye su obra con notas y acordes largos e indica la utilización del pedal para alargar el sonido, logrando así recordarnos las campanas de la catedral.

Darío sigue utilizando elementos marinos y musicales:

El sol un vidrio redondo y opaco, con paso de enfermo camina al cenit; el viento marino descansa en la sombra teniendo de almohada su negro clarín.

En esta parte del poema de Darío, podemos notar otro elemento importante constituido por el tiempo. Notamos un uso temporal de la palabra y de la imagen, una lentitud en todo; nada es rápido, el viento descansa, se detiene, duerme. De una manera parecida, en el Preludio de Debussy, la 
catedral sale despacio hacia la superficie, no hay velocidad, el sonido es lento con su eco, el sonido se reparte lentamente. El compositor no tiene prisa de resolver, lo único que parece interesarle es la imagen interior de algo lento, como se mueven las cosas dentro del agua.

\section{Las ondas que mueven de plomo, debajo del muelle parecen gemir. Sentado en un cable, fumando su pipa, está un marinero pensando en las playas De un vago, lejano, brumoso país.}

Vemos aquí como no urge pensar rápido, más bien se nos presenta la imagen de un hombre que escucha y piensa, que observa, pero lentamente. Todo transcurre con calma, pareciera ser que ese marinero, ¿porqué no?, fuera Debussy,
Es viejo ese lobo. Tostaron su cara
los rayos de fuego del sol de Brasil;
los recios tifones del mar de la China
lo han visto bebiendo su frasco de gin.

En esta parte del poema es evidente el interés por lo exótico en Darío, la distancia, desde Brasil hasta China, la diferencia, el "otro".

Esta es también una de las manifestaciones dentro de la ideología expresada por Debussy: en Rusia descubre el valor armónico y melódico de la escala de tonos enteros y así alarga sus concepciones sonoras. Otra influencia determinante en Debussy fue la de la música del extremo oriente, que escuchó en la Exposición Universal de 1889. El compositor, con muchos otros franceses se interesó por el kampong de Java. La gente iba a admirar, además el gamelang. Debussy fue el primer compositor en admitir, en un 
nivel profundo, la comunicabilidad de las "otras" culturas musicales.

Darío sigue describiendo y proponiéndonos olores:

La espuma impregnada de yodo y salitre, ha tiempo conoce su roja nariz, sus crespos cabellos, sus bíceps de atleta, su gorra de lona, su blusa de dril.

Darío nos describe -y desmonta- la forma y el color a través de la palabra para formar una imagen de la textura. Debussy obtiene el mismo efecto con las notas graves y las notas agudas de unos acordes extensos y abiertos, para describirnos la catedral, la profundidad donde se encuentra, la soledad.

En medio del humo que forma el tabaco, ve el viejo lejano, brumoso país, adonde una tarde caliente y dorada, tendidas las velas, partió el bergantín

Lo que maneja Darío aquí es un estilo distante, difícil de ver, confundido, nublado o borroso, igual que cuando uno ve a través del humo, cuando no está seguro. Debussy, por su lado, en el preludio nos propone una catedral dentro del agua que estamos imaginándonos, que no logramos ver bien.

La siesta del trópico, El lobo se aduerme.

Ya todo lo envuelve la gama del gris.

Parece que un suave $u$ enorme esfumino del curvo horizonte borrara el confín.

Aquí descansa el poema en su tonalidad, la tonalidad que escogió Darío para su obra: el color gris. La imagen del 
gris nos envuelve a todos, y no hay fronteras, es un color infinito, Allí mismo es donde Debussy nos hace llegar con un crescendo, mientras la catedral emerge a la superficie, con un coral fortissimo.

\section{La siesta del trópico. La vieja cigarra Ensaya su ronca guitarra senil, y el grillo preludia un solo monótono en la única cuerda en su violín.}

El binomio música y palabra se hacen presentes aquí, es la naturaleza la que suena, la que canta y cierra un poema. Es un sonido pequeño, intimo, que trabaja a través de los versos para describirnos una imagen.

Pedro Salinas (1998, pág. 111) dice: Al igual que la Cathédrale Engloutie debussyana, al igual del campaneo de la catedral de su León, Nicaragua, sumergida por capas y capas de años y lugares, seguía soñando misteriosamente en el fondo de su corazón, en las horas en que calla el tumbo del mar presente.

De igual manera Debussy y Darío, en sus diferentes entornos geográficos y culturales logran dibujar campanadas, espacios enormes, colores difuminados en los tonos del gris. No es un mar presente, efectivo, el que nos rodea, es un mar imaginado.

Debussy y Darío se unen con un poema y un preludio, aunque nunca se vieron.

\section{Bibliografía}

Debussy, Claude (1986) Il signor Croche, antidilettante. Pordenone: Studio tesi.

Magnani, Luigi (1978) La musica in Proust. Turín: Einaudi

Salinas, Pablo (1998)

Strobel, Heinrich (1990) Claude Debussy. Madrid: Alianza Editores. 